\title{
1. Competition law and the economic characteristics of developing countries
}

\author{
Simon J. Evenett*
}

\subsection{INTRODUCTION}

During the past 20 years many developing countries have adopted competition laws and begun enforcing them. Despite this, the role of competition law and its enforcement remains contested, even among the practitioners and analysts sympathetic to this body of economic regulation. The legitimate objectives, enforcement priorities, methods of implementation of competition law in developing countries, and the extent to which they should depart from those in industrialized countries, are debated to this day. ${ }^{1}$

While no claim is made to settle these profound matters in this chapter, the goal here is to document many of the economic characteristics of developing countries that might be relevant for debates over the role of competition law and its enforcement. Drawing upon databases from the World Bank and elsewhere, differences between countries at different levels of development (as proxied by levels of gross national income per capita) are documented and discussed.

While the focus here is on the characteristics of different groups of countries, readers should bear in mind that there is often considerable intra-group variation. This is a technocratic way of saying that not every developing country is alike. Indeed, the members of subsets of developing

* I thank Fabian Feger for assisting me in the research for this chapter. I also thank Michal Gal for comments on an earlier draft on this chapter and to workshop participants for comments on a presentation that led to this chapter. All remaining errors are my own.

1 An overview of that debate which cites many of the important contributors to this literature is Oliver Budzinksi and Mayram Haji Ali Beji, Competition Policy Agenda for Industrializing Countries, IImenau Economics Discussion Paper No. 81 (Illmenau University of Technology, May 2013). 
countries, such as the least developed countries, are not alike either. Still, practitioners and analysts familiar with one group of countries' circumstances (for example, high income industrialized countries) may find it valuable to be acquainted with the different circumstances in countries with different per capita income levels.

There are also limits as to what can be inferred from the summary statistics presented here. For example, the observation that the agricultural share of national output is higher in developing countries than in industrialized countries should not be taken to imply that anti-competitive practices in that sector must be a priority for competition law enforcement. After all, the reason that the tertiary sector in a developing country is so small could be because entrenched monopolies are stifling its growth. As always, care is needed in interpreting data. That such data need not immediately support a single interpretation should be taken as an invitation to investigate further. The approach taken here supports a more evidence-driven assessment of the enforcement priorities and methods for competition law in developing countries.

The rest of this chapter is organized as follows. The next section contains some observations on the debate over the role of competition law and enforcement in developing countries and argues that evidence can help take discussions forward. The third section employs a variety of internationally available data to explore the cross-country variation in certain national characteristics that are likely to be relevant for competition law and enforcement. Concluding remarks are presented at section 1.4.

\subsection{DIALOGUE OF THE DEAF ON COMPETITION LAW AND DEVELOPMENT}

It is difficult to believe that many who attend the numerous international meetings on competition law and development (organized by the International Competition Network, the Organisation for Economic Cooperation and Development, and the United Nations Conference on Trade and Development to mention only the major global bodies involved) are satisfied with the resulting deliberations. This isn't just a matter of debate as the views expressed influence the design and execution of capacity building initiatives and the like.

On the one hand, many practitioners and officials from industrialized countries advocate the adoption of economic efficiency as the objective of competition law enforcement and are sceptical of attempts to employ non-efficiency-based objectives, such as poverty reduction, in the drafting and conduct of competition law in developing countries. Plus they find 
that many development-related objectives are vague and difficult to operationalize. $^{2}$

When it comes to the priorities of younger competition agencies, the argument is frequently made that they should engage in competition advocacy and, at most, cartel enforcement. The not so subtle implication is that merger control and abuse of a dominant position or monopolization cases are beyond the technical capabilities of younger enforcement agencies. The latter position seems to be driven more by the complexity of the trade-offs associated with enforcement decision-making than by an empirical assessment of the form of the most significant anti-competitive practices afflicting developing countries.

On the other hand, many experts and officials from developing countries argue that competition law must be put in the service of socio- and economic development and are frustrated by what they see as the narrowness of an efficiency objective. ${ }^{3}$ For some, the commitment to the Millennium Development Goals is taken seriously and they want competition law to play its part. Some go even further and argue that unless competition agencies are seen to be making a direct contribution to the development of their country, then political support for competition law and its enforcement may decline so much that it threatens the very existence of this form of economic regulation.

Even those from developing countries who advocate efficiency objectives would also argue that trade-offs exist between short-term and longer term efficiency in ways that experts from industrialized countries acknowledge rarely. Many governments in developing countries openly pursue industrial policies and competition agencies have to adjust to this reality. Pouring cold water on industry policy and criticizing attempts by competition agencies to take it into account are not very helpful, so the argument goes.

The suggestion that competition agencies in developing countries should focus on competition advocacy and cartel enforcement is brushed off by those who argue that this misses important developments in the economic structure of those countries. Moreover, this argument is seen by some in developing countries as self-serving as it implies that developing countries

2 See, for example, the following speech by the Chairwoman of the US Federal Trade Commission, Edith Ramirez, 'Core Competition Agency Principles: Lessons Learned at the FTC', Antitrust in Asia Conference, Beijing, China, 22 May 2014.

3 A recent example of this line of argument is A. Singh, 'Competition, Competition Policy, Competitiveness, Globalisation and Development' (mimeo, University of Cambridge, 3 December 2013). 
not review mergers by firms headquartered in industrialized countries that also have operations in emerging markets.

All in all, the impression often given is that of a dialogue of the deaf. Rarely does anyone step back and question whether the distilled wisdom on competition law and enforcement from one group of countries would be relevant for a different group of countries. Perhaps there is the implied assumption that all market-based economies work the same way? Or maybe there is the assumption that such economies should work the same way and that economic regulation should follow a single set of best practices? In other areas of economic law, for example, intellectual property rights law, whether better practices in one jurisdiction can or should be transplanted to another jurisdiction is given far more attention. ${ }^{4}$

One reason for doubting the wholesale and unqualified transplanting of one way of enforcing competition law is that national economic circumstances differ. Apart from glaring differences in per capita income levels, what is the evidence of different economic conditions? One goal of this chapter is to summarize the data on key national circumstances that might have a bearing on the enforcement priorities of competition law in developing countries and on its implementation.

Still, one needs to be careful when assessing evidence on cross-country differences, for competition law is a multifaceted tool and can be adapted to different circumstances. For example, the presence in many developing countries of a large informal sector in certain markets may alter assessments of the number of substitutes available to buyers and therefore the assessment of the market power of incumbent firms. This consideration may not be that important in implementing competition law in the highest income countries and, consequently, this is a matter where developing country agencies may learn more from each other than from the most established competition agencies.

Overall, a better understanding of the similarities and differences between economic circumstances of developing and industrialized economies may support more constructive discussions on the appropriate enforcement of competition law.

4 See the sizeable literature on the 'transplant effect' on laws across jurisdictions. Google Scholar reports over 1,400 works containing the phrase 'transplant effect' and the word 'law'. The combination of the phrases 'economic development' and 'transplant effect' is found in just under 1,100 works in Google Scholar. 


\subsection{EVIDENCE ON THE CROSS-COUNTRY DIFFERENCES IN NATIONAL CIRCUMSTANCES OF POTENTIAL RELEVANCE TO COMPETITION LAW}

The goal here is to provide empirical evidence on a range of national circumstances or characteristics that might differ markedly across countries at different stages of development and that might have a bearing on the priorities and implementation of competition law. Some of the circumstances considered relate to indicators of policy stance, whereas others are variables that are probably best thought of as the outcome of policy, economic, historical and institutional factors, such as the sectoral composition of national income. However, before describing the empirical counterparts to the selected circumstances, another important matter must be addressed.

Rather than take a position on what is a 'developing' country and what is an 'industrialized' country, a matter which is potentially loaded with all sorts of value judgements, I compare across groups of countries with roughly similar levels of per capita income. This has the advantage of facilitating consistent comparisons across groups of countries. However, readers should be uncomfortable with any implication that the level of development can be collapsed to a single metric.

In this chapter I follow the World Bank's classification of counties into four groups. For the World Bank, countries where the gross national income per capita is below US $\$ 1,035$ per annum are classified as 'low income' countries. Countries with gross national income per capita between US $\$ 1,036$ and 4,085 are classified by the World Bank as 'lower middle income'. Likewise, a gross national income per capita in the range US $\$ 4,086$ to 12,615 results in a country being classified 'upper middle income' by the World Bank. Countries with gross national incomes of US\$12,616 or more are classified 'high income'. Notice the World Bank sensibly avoids labelling countries 'developing', 'advanced', etc.

Table 1.1 reports the number of countries falling within each income classification. The low income category contains 36 jurisdictions, making it smaller than the United Nations-created category 'least developed countries'. At the other end of the income spectrum, the World Bank's high income category includes more jurisdictions than are members of the Organisation for Economic Cooperation and Development.

That each income classification includes a sizeable number of countries raises the question as to whether the within-classification variation of any variable is smaller or larger than the variation between income 
Table 1.1 Number of countries in each income category

\begin{tabular}{lc}
\hline Income classification & Number of countries \\
\hline Low income & 36 \\
Lower middle income & 48 \\
Upper middle income & 55 \\
High income & 75 \\
\hline
\end{tabular}

Source: World Bank, World Development Indicators database.

classifications. In what follows, such 'within' variation is frequently referred to.

I now turn to data on various circumstances that might have a bearing on the prevalence and sources of anti-competitive practices, with direct implications for the priorities of competition agencies.

\subsubsection{Sectoral Composition of National Output}

The first indicator relates to the sectors where value is created within an economy. The long-established tendency for the agricultural sector to decline in relative economic importance as a country's per capita income rises is confirmed in Figure 1.1. In low income countries the average agricultural sector accounts for just over 32 per cent of national GDP. In the average high income country that share is just 2 per cent. The combination of productivity growth in agriculture and relatively price-insensitive demand for food accounts for this falling share of GDP, except perhaps in countries where food is produced cheaply enough to be able to be exported to foreign markets. Even then foreign import barriers may limit food exports and, therefore, the size of a nation's agricultural sector.

For sure, there is a variation within each income classification in the contribution of agriculture to national GDP. Still, the broad tendency shown in Figure 1.1 is confirmed. Among low income countries the percentage of GDP accounted for by agriculture ranges from 17.8 to 57.3, whereas the comparable range for high income countries is zero to 8.0.

The pronounced tendency for the agricultural sector's contribution to diminish over time can be substantiated in intertemporal data for many countries. Figure 1.2 shows how the sectoral composition of Chinese GDP has changed since 1990. As agriculture's share has declined it has been taken up by the service sector. It should be noted, however, that it is often argued that China's service sector contributes less to its GDP than other countries at a similar level of per capita income; or to put it differently, the 


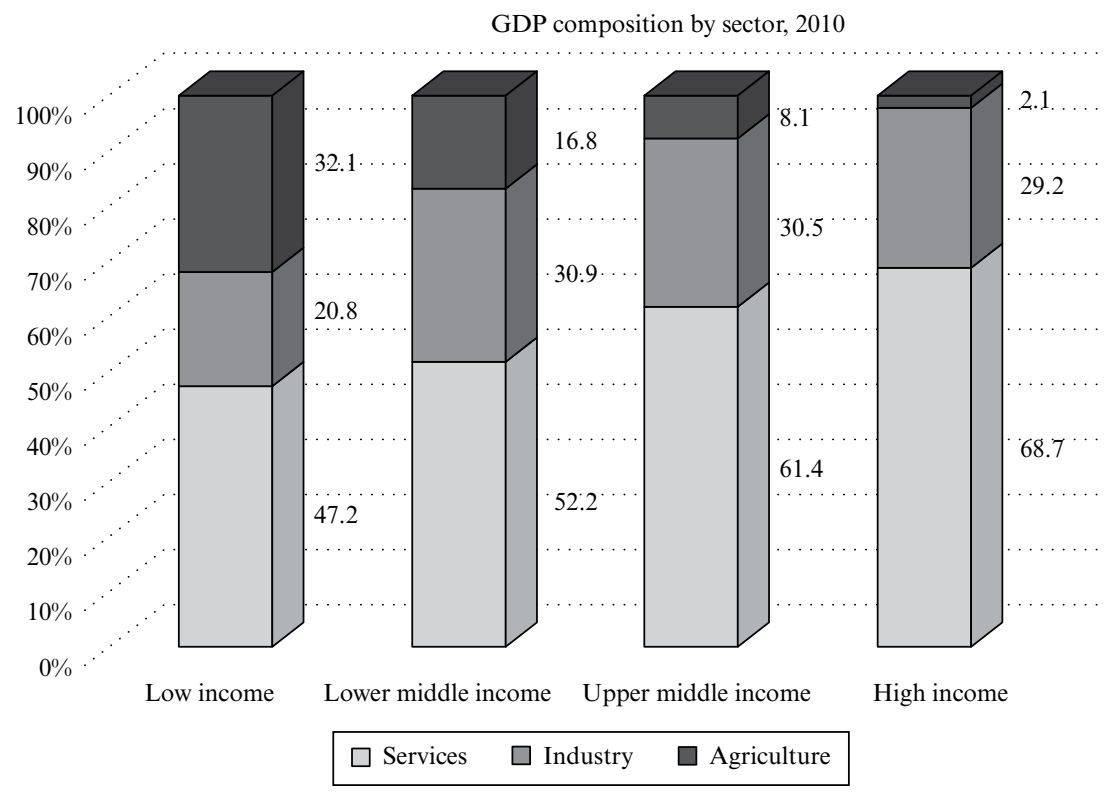

Source: World Bank, World Development Indicators database.

\section{Figure 1.1 Countries with higher average per capita incomes tend to have smaller agricultural sectors}

share of manufacturing in Chinese GDP has not declined as its per capita income has risen.

It might be tempting to conclude from this data that, to the extent that the anti-competitive practices differ across sectors of the economy, then the enforcement priorities of competition agencies will differ across income classifications. There may be something in this argument, if indeed it can also be shown that the patterns of anti-competitive practices do differ across sectors.

Some might be tempted to argue that this data shows that for low income countries 'agriculture is where the action is' and that competition law enforcement should target that sector. I would caution against jumping to that conclusion for several reasons, not the least of which is that the sectoral composition of GDP is endogenous - and that the size of the service and manufacturing sector may be held back by anti-competitive practices. This is not to deny the importance of tackling such practices in the agricultural sector, where large fractions of national workforces are employed in developing countries. 


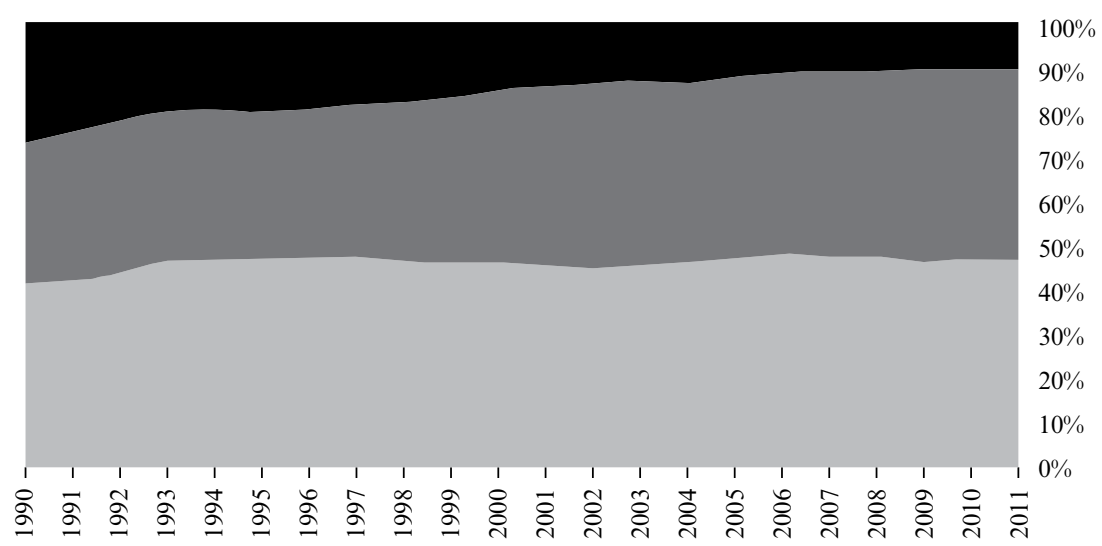

Industry, value added ( $\%$ of GDP)

Services, etc., value added ( $\%$ of GDP)

Agriculture, value added ( $\%$ of GDP)

Source: World Bank, World Development Indicators database.

Figure 1.2 Agriculture's contribution to Chinese GDP has fallen steadily over time

Another important point to take away from Figures 1.1 and 1.2 is that resources tend to be reallocated between sectors as per capita incomes rise, shifting presumably from lower value-added activities to highervalue added activities, thereby ultimately supporting higher living standards. Therefore, it may be useful to think through what role competition law and its enforcement could play in facilitating such resource reallocation or, as it is commonly referred to in the development literature, the structural transformation of national economies. Incidentally, since one of the rationales often given for industrial policy in developing countries is facilitating this transformation, there may be some unexplored complementarities here between competition law and certain industrial policies.

\subsubsection{Composition of Personal Spending}

The second characteristic of developing countries that I will discuss is motivated by the often-heard claim that competition law is to safeguard the interests of customers. This begs the question as to whether personal spending patterns vary across levels of income. It turns out that they do. Figure 1.3 shows that the personal expenditure share on food falls 


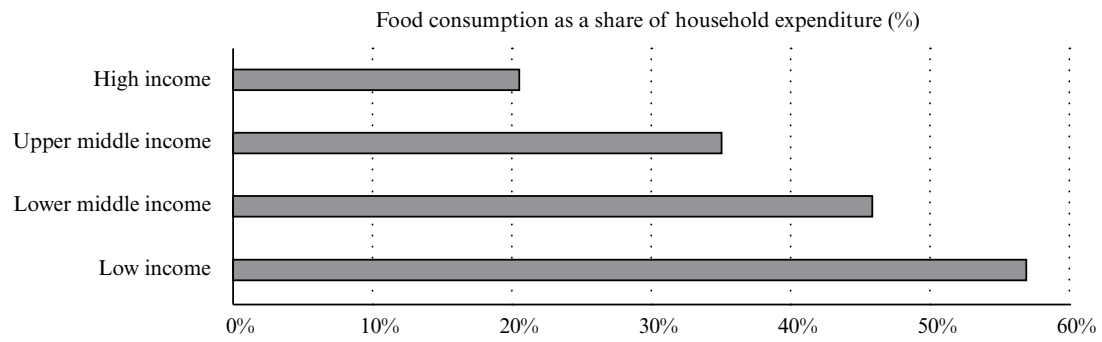

Source: Economist Intelligence Unit, Global Security Index 2013. Differences in data availability across countries meant that the averages were constructed using data from different years.

Figure 1.3 Food spending shares are consistent with Engel's Law

Table 1.2 Spending on 'essentials' is lower in higher per capita income countries

\begin{tabular}{lcccc}
\hline Income classification & $\begin{array}{c}\text { Food, non alcoholic } \\
\text { beverages }\end{array}$ & $\begin{array}{c}\text { Clothing, } \\
\text { footwear }\end{array}$ & Housing & $\begin{array}{c}\text { All other } \\
\text { items }\end{array}$ \\
\hline Low income & $54.0 \%$ & $6.2 \%$ & $14.5 \%$ & $25.3 \%$ \\
Lower middle income & $52.9 \%$ & $5.8 \%$ & $11.8 \%$ & $29.5 \%$ \\
Upper middle income & $34.6 \%$ & $6.2 \%$ & $17.6 \%$ & $41.5 \%$ \\
High income & $17.5 \%$ & $5.2 \%$ & $19.4 \%$ & $57.9 \%$ \\
\hline
\end{tabular}

Source: International Labour Organization, Labour Statistics Database: Household Income and Expenditure Statistics. The data in this table reports the average percentage of household income spent on each category.

systematically as average national per capita incomes rise, a finding that Ernst Engel first noticed in the nineteenth century. ${ }^{5}$

More generally, the poor tend to spend much of their income on food, non-alcoholic beverages, clothing, footwear, and shelter (housing). Data from the International Labour Organization was used to compute the average shares of income spent on these products and services for each income classification and the results are reported in Table 1.2.

5 E. Engel, 'Die Productions- und Consumtionsverhältnisse des Königreichs Sachsen' (1857) 8-9 Zeitschrift des statistischen Bureaus des Königlich Sächsischen Ministerium des Inneren 28. 


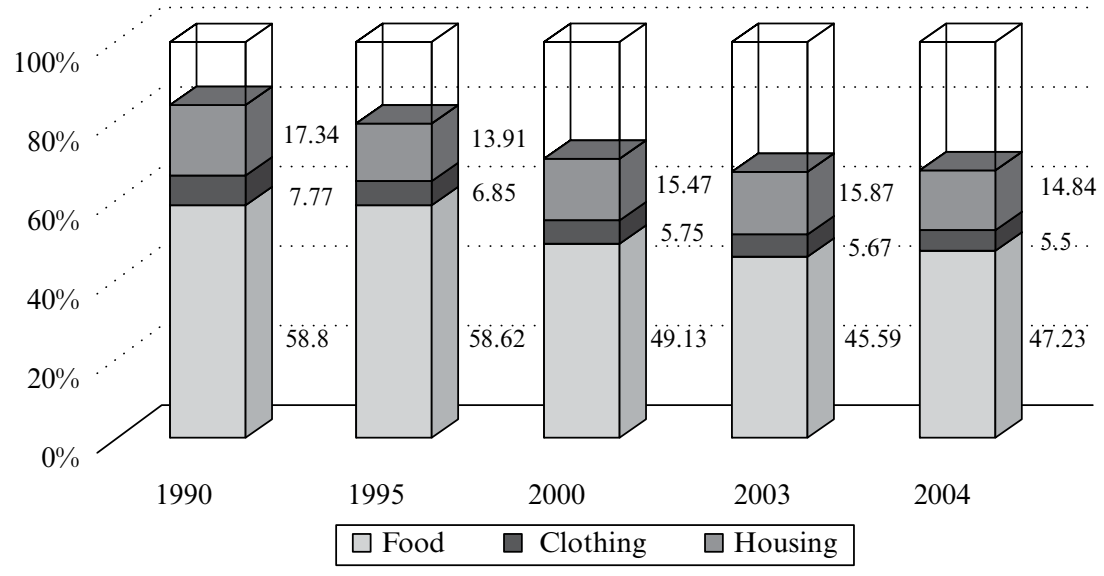

Source: National Bureau of Statistics, China Statistics 2005.

Figure 1.4 Food, clothing and housing expenditure shares in rural China

Tracking a country's personal expenditure shares over time frequently bears out this pattern as well. Figure 1.4 was constructed using data from households in rural China and shows that, over the 15-year period from 1990 to 2004, the share of spending on food, clothing and housing fell sharply. Still, even in 2004 these three categories alone accounted for two-thirds of spending by rural Chinese households.

To the extent that competition law seeks to safeguard the welfare of individual buyers, then, in the lowest income countries the fact that so much spending is concentrated on a few product categories suggests where the greatest direct impact of competition law enforcement on living standards might be. Perhaps it might be better to put the matter differently: the case for devoting substantial enforcement resources to tackling anti-competitive practices in sectors where personal spending shares are tiny requires particular scrutiny.

Of course, the focus here on personal expenditure shares should not blind competition agencies to the harm done by anti-competitive practices affecting corporate buyers. ${ }^{6}$ Indeed, to the extent that harm to the latter is passed on as higher prices to final consumers, even a consumer-oriented

6 Plus one should not fall into the trap of assuming that because expenditure shares on a product or class of products are high that enforcement action will necessarily deliver large changes in consumer welfare. There is many a slip between cup and lip, as the saying goes. 
Table 1.3 Average, maximum and minimum shares of national income attributed to unregistered business (the 'shadow economy'), by income classification

\begin{tabular}{lccc}
\hline Income classification & Average & Maximum in class & Minimum in class \\
\hline Low income & $41.2 \%$ & $62.8 \%$ & $29.0 \%$ \\
Lower middle income & $35.8 \%$ & $63.3 \%$ & $13.9 \%$ \\
Upper middle income & $32.6 \%$ & $58.7 \%$ & $11.5 \%$ \\
High income & $19.9 \%$ & $45.3 \%$ & $8.1 \%$ \\
\hline
\end{tabular}

Source: C. Elgin and O. Öztunah, Shadow Economies around the World: Model Based Estimates (2012).

perspective would not preclude enforcement against anti-competitive practices harming firms.

\subsubsection{Extent of the 'Informal' Economy}

Turning now from output and expenditure shares to factors affecting conditions of competition, the next characteristic explored is the so-called informal or shadow economy. Analysts of these matters tend to stress that there need not be anything underhand in unregistered commercial activity and that may be so. However, my interest in this matter is that competition from unregistered firms is still competition and that actual or potential rivalry is often an important consideration to be taken into account in certain enforcement matters.

Estimating the contribution of unregistered corporate activity to national income or value-added is difficult precisely because the firms in question do not report information to the government and may not pay taxes (often another source of information). Inevitably, then, any estimates generated should come with 'health warnings' for readers, reflecting underlying assumptions made used to generate any estimates and associated statistical uncertainty.

Table 1.3 reports some recent estimates by income classification of the average, maximum, and minimum contribution of the 'shadow economy' to national income. While the average contribution of unregistered firms to national GDP tends to be lower in higher per capita income categories, there is substantial variation across firms in each income classification. This data also suggests that some high income countries have large informal sectors, begging the question as to whether and how their competition 


\section{Table 1.4 There is considerable variation in certain barriers to entry across countries}

\begin{tabular}{lccc}
\hline Income classification & $\begin{array}{c}\text { Number of } \\
\text { procedural steps }\end{array}$ & $\begin{array}{c}\text { Time to } \\
\text { start-up (days) }\end{array}$ & $\begin{array}{c}\text { Costs of start-up (\% } \\
\text { of GNI per capita) }\end{array}$ \\
\hline Low income & 7.31 & 30.70 & 87.70 \\
Lower middle income & 7.96 & 30.48 & 36.10 \\
Upper middle income & 7.62 & 41.40 & 17.55 \\
High income & 6.37 & 17.61 & 6.76 \\
\hline
\end{tabular}

Source: World Bank, Doing Business database.

agencies have taken such informality into account during certain enforcement actions and market analyses. ${ }^{7}$

\subsubsection{Barriers to Entry}

Competition agencies often take into account the barriers to entering markets when assessing the potential exercise of market power. For over a decade now the World Bank has undertaken surveys of the costs, time and hurdles that must be met before a firm can be legally established. As Table 1.4 shows, there is considerable variation across groups of countries in the costs of starting up a business. There is considerably less variation in the number of procedural steps that must be followed. When it comes to the number of days necessary to set up a business the high income countries stand out, implying much greater time costs for establishing a firm in lower income countries.

Data for the years 2007 to 2012 was examined to detect any patterns of intertemporal variation. In each of the three measures of barriers to entry in Table 1.4, there was a generalized tendency for barriers to entry to fall over time in each income classification. However, the rate of improvement was fastest among the low income group of nations. Indeed, such is the rate of erosion of barriers to entry among that group that by 2012 the average for the low income class was no different from the middle income groups, except for the costs of starting up a business. Even with respect to

7 This data source also shows that there is a gradual decline in the average size of the shadow economy over time in every group of countries. The key word in the last sentence is 'gradual'. In short, to the extent that the informal sector poses a challenge for competition agencies, it is not going away quickly. 


\section{Table 1.5 Barriers to import competition are highest in low per capita income countries}

\begin{tabular}{lccc}
\hline Income classification & $\begin{array}{c}\text { Number of } \\
\text { documents to import }\end{array}$ & $\begin{array}{c}\text { Time to import } \\
\text { (days) }\end{array}$ & $\begin{array}{c}\text { Cost to import } \\
\text { (US\$ per container) }\end{array}$ \\
\hline Low income & 9.53 & 42.90 & $3,016.00$ \\
Lower middle income & 7.98 & 28.00 & $1,690.44$ \\
Upper middle income & 7.24 & 23.00 & $1,640.68$ \\
High income & 5.80 & 12.04 & $1,145.24$ \\
\hline
\end{tabular}

Source: World Bank, World Development Indicators database.

the latter, these have fallen by approximately 60 per cent in the six years from 2007 to 2012 .

Still, falling barriers to entry does not mean no barriers to entry. There may be a role for competition advocacy by competition agencies in low and middle income countries in promoting further reductions in barriers to entry. As for enforcement, it would be interesting to explore the extent to which higher barriers to entry in low and middle income countries affect the conditions of competition in markets in their economies and whether there are any perceptible differences in terms of effects than in high income countries. The propensity to intervene may be different in jurisdictions where barriers to entry are higher and market forces are less likely to erode the actual or potential market power of incumbents.

\subsubsection{Barriers to Import Competition}

Similar patterns can be found in barriers to entry by imports, one mode of supplying domestic markets. ${ }^{8}$ Table 1.5 reports the average size of three indicators of barriers to importation, assembled from the World Bank's 'Doing Business' surveys and available as part of the 'World Development Indicators' database. Unlike domestic barriers to entry (see Table 1.4), as far as import barriers are concerned they tend to be lower on average in groups of countries with higher per capita incomes.

8 Other important modes of supply include foreign direct investment (greenfield and mergers and acquisitions); licensing; franchising; and temporary movement of personnel. Each of these modes of supply can be affected by government policies that discriminate against foreign suppliers or domestic firms affiliated with or contracting with foreign firms. The World Bank's Doing Business database contains information on some of these barriers as well. 


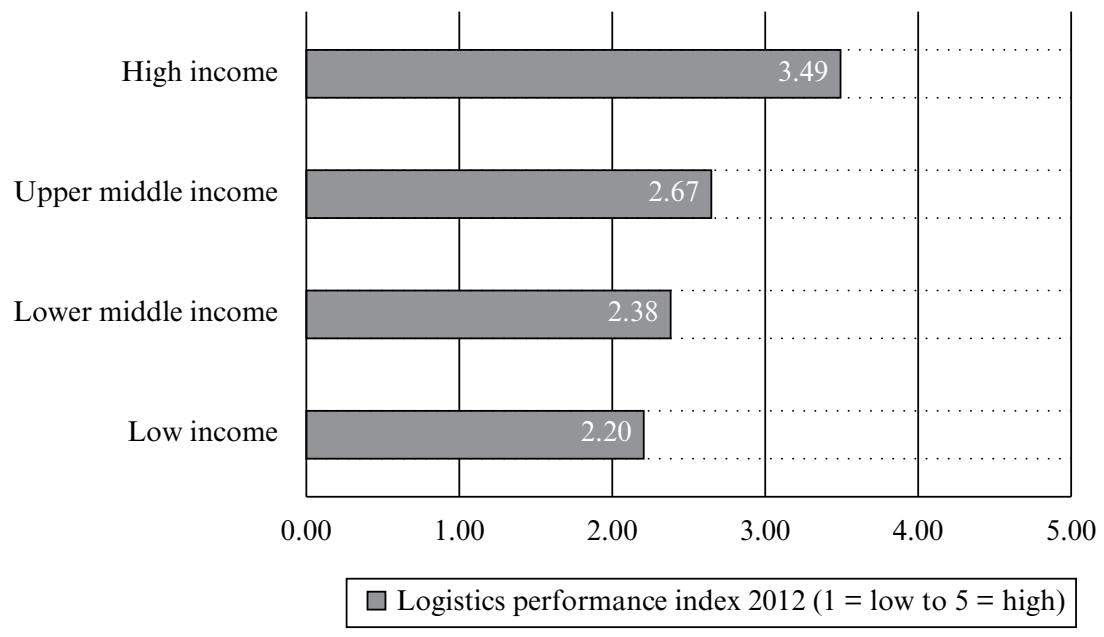

Source: World Bank, World Development Indicators database.

Figure 1.5 The quality of domestic transport infrastructure is higher in higher income countries

\subsubsection{Logistics Infrastructure}

Another factor that fragments markets, possibly within nations as well as between them, is the quality of the logistics infrastructure. In competition law terms, poor transportation infrastructure may limit the distance over which a firm can compete with rivals, thereby limiting the 'extent of the market' as Adam Smith would have put it. Local oligopolies or monopolies can result, all of which ought to be taken into account in competition agencies' assessments of the ability of incumbent firms to exercise market power. Figure 1.5 confirms that, on one index compiled regularly by the World Bank, in 2012 the quality of transport-related infrastructure tended to be lower on average in groups of countries with lower average incomes per capita.

\subsubsection{Assessment}

Overall, there are discernible differences across groups of countries in the structure of production, personal consumption spending, and factors likely to affect the availability of competitive substitutes. For sure, there is variation within each group of countries, so there may well be some developing countries that, on certain criteria, look rather like so-called 
industrial country counterparts. Plus, conditions change over time (both private sector behaviour and public policy), calling for a frequent reexamination of the underlying data.

All of these reasons call into question two polar opposite views. It seems to me that, on the data presented here, the blueprint or working assumptions used to implement and explain competition law in certain high income countries cannot unquestionably be transferred to all low income countries. Enforcement priorities and properly conducted market analyses are likely to give different weights to certain factors, such as availability of competitive substitutes.

Yet, at the same time, it is not clear that all of the better practices developed in high income countries are necessarily irrelevant to all developing countries. Moreover, if 'development' matters then we are entitled to ask what precise objectives there are and the most objective (or least subjective) way to assess whether those objectives are being met and at what cost.

Reflecting on the data presented here does not lead to the type of crisp policy recommendations that some may like. In fact, differentiating between countries on the basis of per capita income or, worse, 'levels of development' may not be that helpful. A more calibrated approach that examined competition law priorities and enforcement practice on a market-by-market basis using objective data to identify more or less similar cases might take the discussion forward. If this is the right approach, then it would make sense to discard assumptions about who should learn from whom.

\subsection{CONCLUDING REMARKS}

For too long discussions on the appropriate role and implementation of competition law in developing countries have been a dialogue of the deaf. For whatever reasons, some have been keen on transplanting their model of competition law and enforcement. Others haven't been keen on receiving advice from abroad and, again, there may be plenty of reasons for that reaction. The consequence is that opportunities to reflect upon enforcement experience may have been lost and international cooperation on competition law and aid effectiveness on technical assistance have fallen short.

In my view, discussions on competition law and development need to be grounded more frequently upon an objective, empirical base. For sure, not everything that is important can be measured and plenty of what can be measured isn't. Still, the competition law toolkit contains a wide range 
of instruments whose application can be adapted to a range of different circumstances. Rather than transplanting blueprints from one jurisdiction to another, it may be better to think of devising recipe books that adapt the known techniques to different ingredients and maybe different tastes. 